\title{
The influence of obtaining and heat treatment conditions on the structure of $\mathrm{As}_{2} \mathrm{~S}_{3}$-SbSI system
}

\author{
V.M. Rubish ${ }^{1}$, L. Bih ${ }^{2}$, O.A. Mykaylo ${ }^{3}$, O.V. Gorina ${ }^{1}$, V.M. Maryan ${ }^{1}$, \\ S.M. Gasinets' ${ }^{1}$, A.M. Solomon ${ }^{4}$, P. Lazor ${ }^{5}$, S.O. Kostyukevych ${ }^{6}$ \\ ${ }^{1}$ Uzhgorod Scientific-Technological Center of the Institute for Information Recording, NAS of Ukraine, \\ 4, Zamkovi Skhody str., 88000 Uzhhorod, Ukraine, e-mail: center.uzh@gmail.com \\ ${ }^{2}$ UFR-PCMI: ceramiques et verres, FST-Errachidia, \\ 52000, B.P. 509, Boutalamine, Errachidia, Morocco \\ ${ }^{3}$ Institute of Solid State Physics \& Chemistry, Uzhhorod National University, \\ 36, Pidgirna str., 88000 Uzhhorod, Ukraine \\ ${ }^{4}$ Institute of Electron Physics, NAS of Ukraine, \\ 21, Universitetska str., 88017 Uzhhorod, Ukraine \\ ${ }^{5}$ Institute of Earth Science, Uppsala University, S-752 36 Uppsala, Sweden \\ ${ }^{6}$ V. Lashkaryov Institute of Semiconductor Physics, NAS of Ukraine, 03028 Kyiv, Ukraine
}

\begin{abstract}
As}_{2} \mathrm{~S}_{3}\right)_{100-x}(\mathrm{SbSI})_{x}(x=80$ and 90$)$ glasses were prepared by cooling homogenized melts from $720 \ldots 750 \mathrm{~K}$ in cold water. Their structure and structural changes under heat treatment of glasses are confirmed by studies of micro-Raman scattering and X-ray diffraction. In the matrix of these glasses, we observed SbSI nanocrystalline inclusions. It has been shown that the sizes of crystalline inclusions are dependent on the heat treatment regimes.
\end{abstract}

Keywords: chalcogenide glasses, ferroelectrics, Raman spectra, X-ray diffraction, structure, nanocrystal.

Manuscript received 09.01.13; revised version received 26.02.13; accepted for publication 19.03.13; published online 25.06.13.

\section{Introduction}

The interest to the studies of glass materials based on antimony sulfoiodide (SbSI) that is the typical representative of the class of $\mathrm{A}^{\mathrm{V}} \mathrm{B}^{\mathrm{VI}} \mathrm{C}^{\mathrm{VII}}$ ferroelectric semiconductors and possesses excellent dielectric, photo-, pyro-, piezo-electric and pyro-optic properties [1] is caused by the possibility of using it as a basic material for production of nonvolatile memory devices, ferroelectric glass ceramics with preset parameters, pyro- and piezo-electric detectors, actuators [2-4].

It was shown that in the matrix of SbSI glass [5] and in the matrix of $\left(\mathrm{As}_{2} \mathrm{~S}_{3}\right)_{100-x}(\mathrm{SbSI})_{x}$, $\left(\mathrm{As}_{2} \mathrm{Se}_{3}\right)_{100-x}(\mathrm{SbSI})_{x},\left(\mathrm{GeS}_{2}\right)_{100-x}(\mathrm{SbSI})_{x}$ glasses [6-11] at the certain thermal treatment temperature and duration regimes one could obtain crystallites of a targeted size and orientation, possessing ferroelectric properties. There is also a report on the fabrication of SbSI crystal inclusions in the matrix of $\mathrm{As}_{2} \mathrm{~S}_{3}$-SbSI $[12,13]$ and $\mathrm{GeS}_{2}$-SbSI [14] glasses under laser beam treatment.

However, obtaining glassy SbSI and $\left(\mathrm{As}_{2} \mathrm{~S}_{3}\right)_{100-x}(\mathrm{SbSI})_{x}, \quad\left(\mathrm{As}_{2} \mathrm{Se}_{3}\right)_{100-x}(\mathrm{SbSI})_{x}$, $\left(\mathrm{GeS}_{2}\right)_{100-x}(\mathrm{SbSI})_{x}$ glasses with $x \geq 80$ encounters considerable technological difficulties due to the high crystallization ability of its melts $[11,12]$. For example, SbSI can be obtained in the glass form only in a hard quenching regime at the melt cooling rates within the range $200 \ldots 300 \mathrm{~K} / \mathrm{s}$ and in the small amounts $(1 \ldots 2 \mathrm{~g})$ $[5,15]$. The structure and physical properties of glasses can be modified in different ways: variations of a ratio of the starting components; preparation of the glasses at the different regimes of synthesis (homogenization temperatures of the melts and melt cooling rates); physical treatments (annealing, optical irradiation, etc.) $[16,17]$.

Earlier we have detected the amorphous nature of the structure of $\left(\mathrm{As}_{2} \mathrm{~S}_{3}\right)_{100-x}(\mathrm{SbSI})_{x}(x=80,90)$ glasses 
that were prepared by cooling the melts at homogenization temperatures 850 to $870 \mathrm{~K}$ in cold water $[8,9]$. The reason lies in too high cooling rates of melts that suppress the nucleation processes in cooled melts.

In this paper, we focused our attention at the influence of glass preparation conditions and heat treatment on formation of SbSI crystals in the matrix of $\left(\mathrm{As}_{2} \mathrm{~S}_{3}\right)_{20}(\mathrm{SbSI})_{80}$ and $\left(\mathrm{As}_{2} \mathrm{~S}_{3}\right)_{10}(\mathrm{SbSI})_{90}$ glasses.

\section{Experimental}

$\left(\mathrm{As}_{2} \mathrm{~S}_{3}\right)_{100-x}(\mathrm{SbSI})_{x}(x=80$ and 90$)$ glasses were prepared using the vacuum melting method $(\sim 0.01 \mathrm{~Pa})$ of the relevant mixture of $\mathrm{As}_{2} \mathrm{~S}_{3}$ and $\mathrm{SbSI}$ components, preliminary synthesized from high-purity elemental substances. Glassy $\mathrm{As}_{2} \mathrm{~S}_{3}$ was obtained by cooling a homogenized (for $48 \mathrm{~h}$ ) melt from $780 \mathrm{~K}$ in air. Polycrystalline SbSI was obtained by slow cooling the homogenized (for $72 \mathrm{~h}$ ) melt from $900 \mathrm{~K}$ to room temperature. $\left(\mathrm{As}_{2} \mathrm{~S}_{3}\right)_{100-x}(\mathrm{SbSI})_{x}$ melts were homogenized at $720 \ldots 750 \mathrm{~K}$ for $24 \mathrm{~h}$. The melts were periodically stirred. Cooling the melts was carried out in cold water.

Raman spectra were measured using the microRaman spectrometer LABRAM and $\mathrm{He}-\mathrm{Ne}$ laser $(\lambda=$ $632.8 \mathrm{~nm})$. Used in these measurement was laser radiation of a low power $(P<3 \mathrm{~mW})$. In this case, the samples were not undergone to photostructural transformations as well as the heating the samples.

$\mathrm{X}$-ray diffraction studies of glassy, crystallized and crystalline materials were carried out on a ДРОН-3 Xray apparatus $(\lambda=1.5418 \AA)$.

\section{Results and discussion}

Raman spectra of $\left(\mathrm{As}_{2} \mathrm{~S}_{3}\right)_{100-x}(\mathrm{SbSI})_{x}$ glasses with $x=80$ and 90 are shown in Fig. 1 (curves 1 and 7). The glass spectrum with $x=80$ contains broad intense bands with the maxima at 110,153 and $315 \mathrm{~cm}^{-1}$ and a feature (as a shoulder) at $363 \mathrm{~cm}^{-1}$ (Fig. 1, curve 7). The Raman spectrum of $x=90$ glass contains similar bands at 111, 155,313 and $363 \mathrm{~cm}^{-1}$ (Fig. 1, curve 1 ).

Previously, the Raman spectra of the same compositions for glasses of the $\mathrm{As}_{2} \mathrm{~S}_{3}$-SbSI system have been investigated $[9,18]$, but they were obtained after quenching the melt from the temperatures of $850 \ldots 870 \mathrm{~K}$ in cold water. In this case, Raman spectra performed in 180-degree geometry using a spectrophotometer DFS-24 and $\mathrm{He}-\mathrm{Ne}$ laser $(\lambda=$ $630 \mathrm{~nm}$ ) at the room temperature. The intense bands at $314 \ldots 316$ and $156 \ldots 160 \mathrm{~cm}^{-1}$ and the weak features at the $206 \ldots 209,360 \ldots 367$ and $426 \ldots 493 \mathrm{~cm}^{-1}$ were found in Raman spectra of these glasses. The bands at $156 \ldots 160$ and $206 \ldots 209 \mathrm{~cm}^{-1}$ are due to the vibrations of $\mathrm{Sb}$ and $\mathrm{I}$ atomic pairs, and As and I ones in the trigonal pyramids of $\mathrm{SbI}_{3}$ and $\mathrm{AsI}_{3}$, respectively, while the bands in the region of $314 . .316 \mathrm{~cm}^{-1}$ are responsible for the vibrations of atomic pairs of antimony, arsenic and sulfur in the structural groups of $\mathrm{SbS}_{3}$ and $\mathrm{AsS}_{3}$, interconnected via two coordinated sulfur atoms. Note that in $\mathrm{As}_{2} \mathrm{~S}_{3}$ glass a broad band observed at $343 \mathrm{~cm}^{-1}$ is related to the symmetric stretching vibrational modes of $\mathrm{AsS}_{3 / 2}$ pyramids $\left(\mathrm{AsS}_{3}\right.$ pyramids linked together by As - S-As bonds) [19-21]. In Raman spectra of $\mathrm{Sb}_{2} \mathrm{~S}_{3}$ glass, the intense broad band caused by vibrations of $\mathrm{SbS}_{3 / 2}$ structural groups is observed at $290 \ldots 293 \mathrm{~cm}^{-1}[17,22]$. The presence of weak features at $365 \ldots 367$ and $426 \ldots 493 \mathrm{~cm}^{-1}$ indicates an existence in the matrix of $\mathrm{As}_{2} \mathrm{~S}_{3}$-SbSI glasses the certain amount of structural fragments with homopolar bonds As - As and S-S. In Raman spectra of studied glasses, there were not observed the features that could indicate the existence in the matrix of glasses the ternary chain structural units of $\mathrm{SbS}_{2 / 2} \mathrm{I}$, which built the crystalline lattice of SbSI $[1,23]$. Raman spectra and Xray powder diffraction patterns of the annealed glasses demonstrated the features that were characteristic for crystalline SbSI $[8,9,18]$.

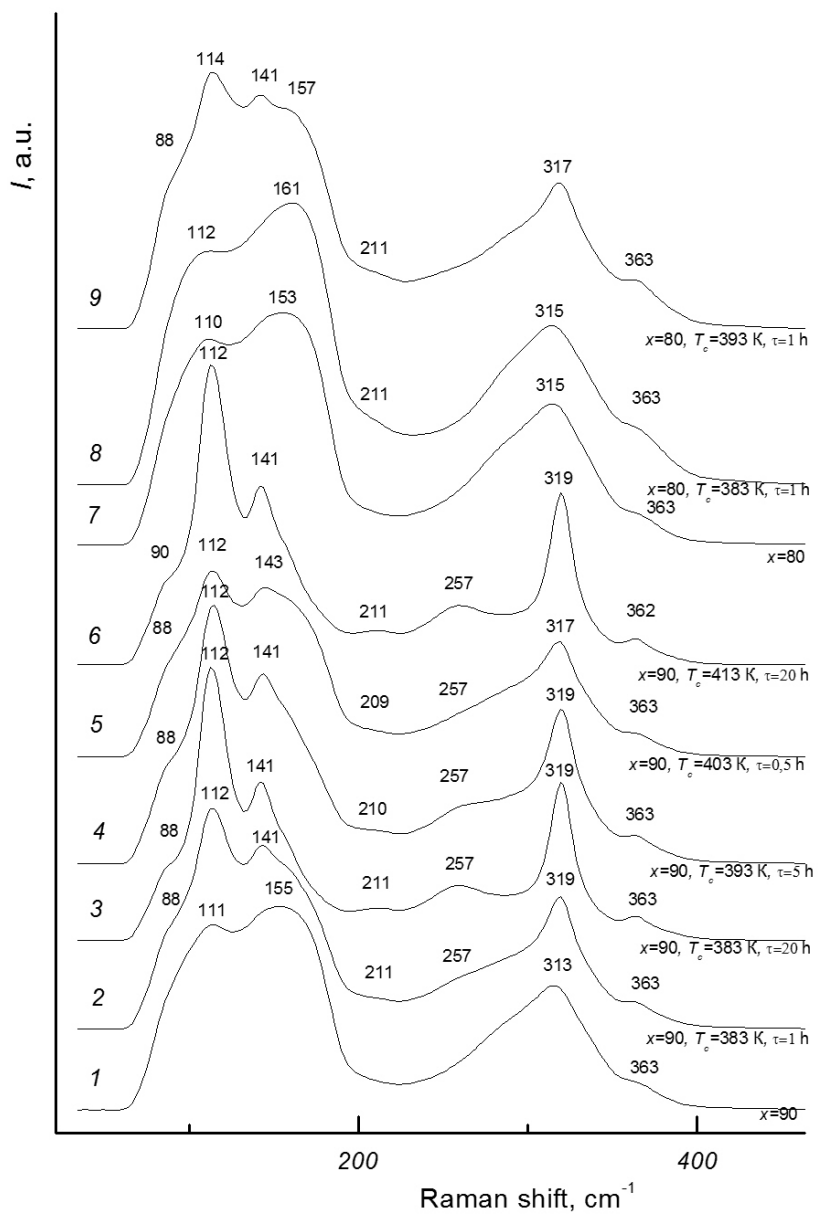

Fig. 1. Raman spectra of as-prepared $(1,7)$ and crystallized at the different annealing temperatures $T_{c}$ and times $\tau(2-6,8,9)$ $\left(\mathrm{As}_{2} \mathrm{~S}_{3}\right)_{100-x}(\mathrm{SbSI})_{x}$ glasses. 


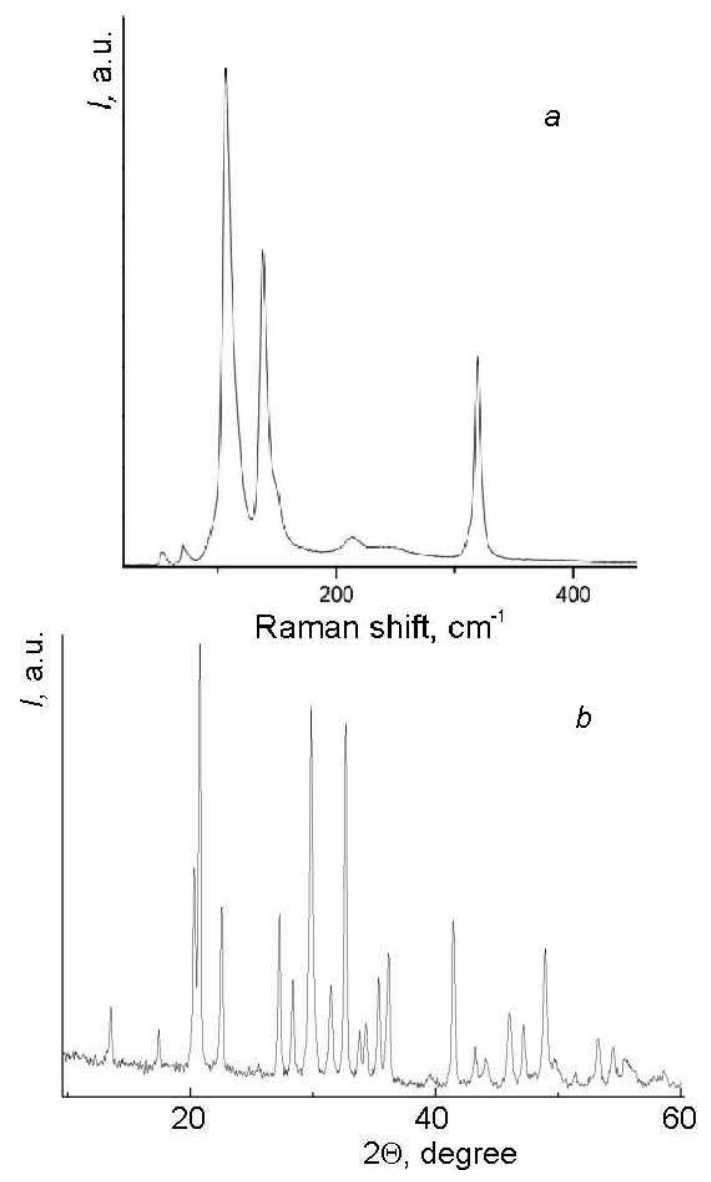

Fig. 2. Raman spectra (a) and X-ray powder diffraction pattern $(b)$ of polycrystalline SbSI.

As a result of these studies, it was concluded that the glasses of $\mathrm{As}_{2} \mathrm{~S}_{3}$-SbSI system have the nanoheterogeneous structure. The matrix of these glasses is built basically just of binary structural groups of $\mathrm{Sb}(\mathrm{As}) \mathrm{S}_{3 / 2}$ and $\mathrm{Sb}(\mathrm{As}) \mathrm{I}_{3}$, also contains small amounts of molecular fragments with homopolar As - As and S-S bonds. The breaking and switching of $\mathrm{As}-\mathrm{S}, \mathrm{Sb}-\mathrm{S}$, As-I, Sb-I chemical bonds in binary structural groups occur when heating in the temperature range of $T_{g}-T_{c}$ with simultaneous formation of the triple chain groups $\mathrm{SbS}_{2 / 2} \mathrm{I}$, which is characteristic for sulfoiodide antimony crystals.

A comparison of Raman spectra of $\left(\mathrm{As}_{2} \mathrm{~S}_{3}\right)_{100-x}(\mathrm{SbSI})_{x}(x=80$ and 90$)$ glasses and the data presented in $[9,18]$ shows that the spectra of glasses, obtained at the melt homogenization temperatures $720 \ldots 750 \mathrm{~K}$, differ from the Raman spectra for the same composition glasses but obtained at homogenization temperatures $850 \ldots 870 \mathrm{~K}$ by the presence of the additional band with maximum at $111(x=90)$ and 110 $(x=80) \mathrm{cm}^{-1}$. The similar band $\left(107 \ldots 110 \mathrm{~cm}^{-1}\right)$ is observed in the Raman spectra of the single crystal $[24,25]$ and polycrystalline antimony sulfoiodide (Fig. 2a), also in crystallized glasses of the $\mathrm{As}_{2} \mathrm{~S}_{3}$-SbSI system $[8,9,18]$. This fact may testify to the presence of nanocrystalline inclusions of SbSI in the matrix glasses, obtained in less rigid hardening conditions. In the course of cooling the melts from lower homogenization temperatures $(700$ to $720 \mathrm{~K})$, and, accordingly, at lower cooling rates, it wasn't possible to completely suppress the processes of nucleation and crystal growth. The strong smeared band at $110 \ldots 111 \mathrm{~cm}^{-1}$ may indicate the existence of nanosize crystals.

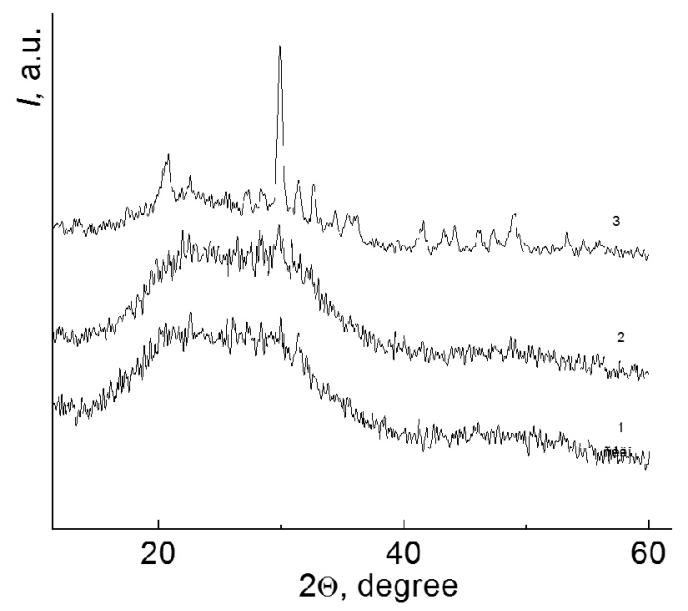

Fig. 3. X-ray powder diffraction patterns of as-prepared (1) and crystallized $(2,3)\left(\mathrm{As}_{2} \mathrm{~S}_{3}\right)_{20}(\mathrm{SbSI})_{80}$ glasses. The annealing temperature $T_{a}$ and annealing time $\tau: 2-383 \mathrm{~K}, 1 \mathrm{~h} ; 3-393 \mathrm{~K}$, $1 \mathrm{~h}$.

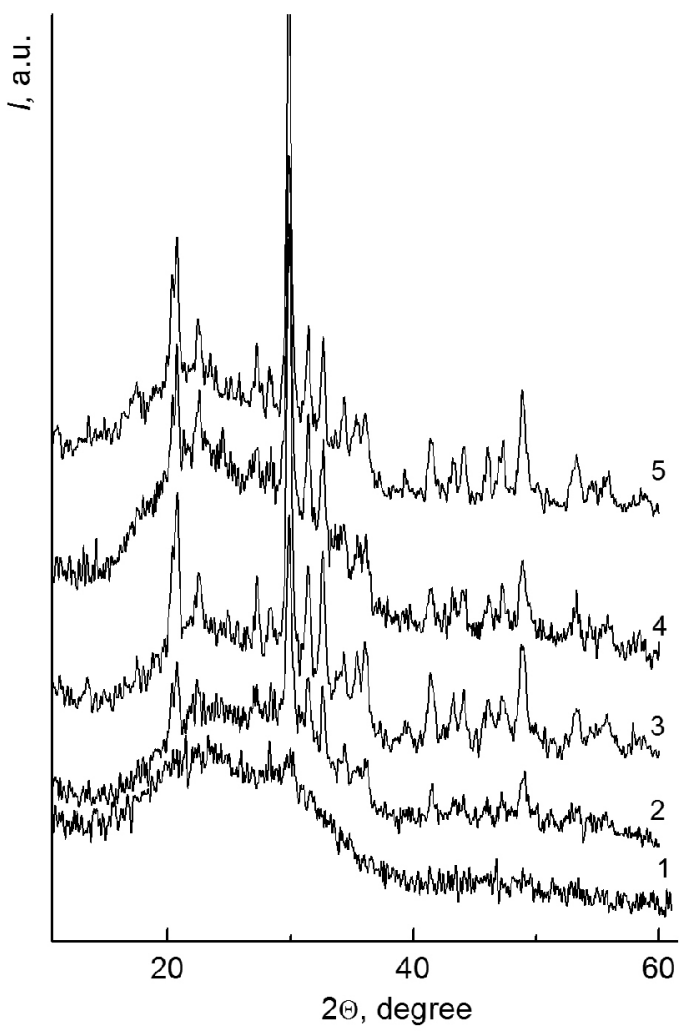

Fig. 4. X-ray powder diffraction patterns of as-prepared (1) and annealed $(2-5)\left(\mathrm{As}_{2} \mathrm{~S}_{3}\right)_{10}(\mathrm{SbSI})_{90}$ glasses. The annealing temperature $T_{a}$ and annealing time $\tau: 2-383 \mathrm{~K}, 1 \mathrm{~h} ; 3-383 \mathrm{~K}$, $20 \mathrm{~h} ; 4-393 \mathrm{~K}, 5 \mathrm{~h} ; 5-413 \mathrm{~K}, 20 \mathrm{~h}$. 
A confirmation of the presence of nanocrystalline SbSI inclusions in the matrix of glasses obtained from 720 to $750 \mathrm{~K}$ could be deduced from the results of X-ray diffraction studies. The X-ray powder diffraction patterns of as-prepared $\left(\mathrm{As}_{2} \mathrm{~S}_{3}\right)_{20}(\mathrm{SbSI})_{80}$ and $\left(\mathrm{As}_{2} \mathrm{~S}_{3}\right)_{10}(\mathrm{SbSI})_{90}$ glasses are shown in Fig. 3 (curve 1 ) and Fig. 4 (curve 1). It is clear that they have the weak reflexes, which positions satisfactorily coincide with the positions of intense lines in the diffraction pattern of polycrystalline SbSI (Fig. 2, curve 6). With increasing the annealing temperature and annealing time, the intensity of reflexes increases (Fig. 3, curves 2 and 3, Fig. 4, curves 2-5), and their half-width decreases. This fact may be considered as the evidence about increasing the size of SbSI crystalline inclusions in the glass matrix.

The Raman spectra of glasses annealed for different times and temperatures contain the intense bands with maxima at $113 \ldots 114,141 \ldots 143$ and $315 \ldots 319 \mathrm{~cm}^{-1}$ (Fig. 1), which clearly indicates the presence of SbSI crystalline inclusions in their matrix. During annealing, the crystallization process is more active and involves diffusion of atoms, and increasing the size of SbSI crystalline inclusions occurs. The evidence of this fact could be the intensity growth of the basic bands in Raman spectra, decrease in their halfwidths and their similarity to those obtained for SbSI crystal [24, 25, 27] (see Fig. 1, curves 2 - 6 and bands at $209 . .211$ and $\left.257 \mathrm{~cm}^{-1}\right)$.

\section{Conclusions}

$\left(\mathrm{As}_{2} \mathrm{~S}_{3}\right)_{100-x}(\mathrm{SbSI})_{x}$ glasses were obtained at lower homogenization temperatures and investigated by microRaman spectroscopy and X-ray diffraction. The presence of nanocrystalline SbSI inclusions in the glassy matrix was detected. The sizes of SbSI crystalline inclusions increase with annealing temperature and annealing time.

\section{References}

1. V.M. Fridkin, Ferroelectrics Semiconductors. Consultans Bureau, New York, 1980.

2. S. Surthi, S. Kotru, R.K. Pandey, SbSI films for ferroelectric memory applications // Integr. Ferroelectr., 48(1), p. 263-269 (2002).

3. P. Muralt, Micromachined infrared detectors based on pyroelectric thin films // Repts. Progr. Phys., 64(10), p. 1339-1388 (2001).

4. M. Nowak, P. Mroczek, P. Duka et al., Using of textured polycrystalline SbSI in actuators // Sens. Actuators A Phys., 150(2), p. 251-256 (2009).

5. V.M. Rubish, Thermostimulated relaxation of SbSI glass matrix // J. Optoelectronics and Advanced Mat., 3(4), p. 941-944 (2001).

6. V.M. Rubish, O.G. Guranich, D.S. Leonov, Ferroelectric inclusions formation in the chalcogenide glass matrix // Nanosystems,
Nanomaterials, Nanotehnologies, 3(4), p. 911-920 (2005), in Ukrainian.

7. V.M. Rubish, Anomalious behaviour of dielectric permittivity of chalcogenide glasses in the vicinity crystallization temperature // Sensor Electronics and Microsystems Technologies, 1, p.62-66 (2007), in Ukrainian.

8. V.M. Rubish, Obtaining and crystallization peculiarities of glasses on the antimony sulfoiodide basis // Physics and Chemistry of Solid State, 8(1), p. 41-46 (2007), in Ukrainian.

9. D.I. Kaynts, A.P. Shpak, V.M. Rubish et al., Formation of ferroelectric nanostructures in $\left(\mathrm{As}_{2} \mathrm{~S}_{3}\right)_{100-x}(\mathrm{SbSI})_{x} \quad$ glassy matrix // Ferroelectrics, 371(1), p. 28-33 (2008).

10. V.M. Rubish, M.Yu. Rigan, S.M. Gasinets et al., Obtaining and crystallization peculiarities of antimony containing chalcogenide glasses // Ferroelectrics, 372(1), p. 87-92 (2008).

11. M. Barj, O.A. Mykaylo, D.I. Kaynts et al., Formation and structure of crystalline inclusions in $\mathrm{As}_{2} \mathrm{~S}_{3}$-SbSI and $\mathrm{As}_{2} \mathrm{Se}_{3}$-SbSI systems glass matrices // J. Non-Cryst. Solids, 357, p. 2232-2234 (2011).

12. Yu.M. Azhniuk, P. Bhandiwad, V.M. Rubish et al., Photoinduced changes in the structure of $\mathrm{As}_{2} \mathrm{~S}_{3}$ based SbSI nanocrystal-containing composites studied by Raman spectroscopy // Ferroelectrics, 416, p. 113-118 (2011).

13. Yu.M. Azhniuk, V. Stoyka, I. Petryshynets et al., SbSI nanocrystal formation in As-Sb-S-I glass under laser beam // Mat. Res. Bull., 47, p. 15201522 (2012).

14. P. Gupta, A. Stone, N. Woodward et al., Laser fabrication of semiconducting ferroelectric single crystal SbSI features on chalcodenide glass // Opt. Mat. Express, 1(4), p. 652-657 (2011).

15. V.M. Rubish, M.V. Dobosh, P.P. Shtets et al., Crystallization parameters of non-crystalline antimony chalcogenides // J. Phys. Studies, 8(2), p. 178-182 (2004).

16. A. Feltz, Amorphe und Glasartige Festkörper. Akademie-Verlag, Berlin, 1983.

17. V.V. Petrov, A.A. Kryuchyn, V.M. Rubish, Materials for Perspective Optoelectronic Devices. Naukova Dumka-Verlag, Kiev, 2012 (in Russian).

18. V.M. Rubish, V.O. Stefanovich, O.G. Guranich et al., Structure investigation of As-Sb-S-I system glasses by Raman spectroscopy // Nanosystems, Nanomaterials, Nanotehnologies, 6(4), p. 11191127 (2008), in Ukrainian.

19. V.M. Rubish, O.G. Guranich, V.V. Rubish, Structure and properties of $\mathrm{As}_{40} \mathrm{~S}_{60-x} \mathrm{Se}_{x}$ glasses // Photoelectronics, 16, p. 41-45 (2007).

20. D.G. Georgiev, P. Boolchand, K.A. Jackson, Intrinsic nanoscale phase separation of bulk $\mathrm{As}_{2} \mathrm{~S}_{3}$ glass // Phil. Mag., 83(25), p. 2941-2953 (2003). 
21. O.A. Mykaylo, O.G. Guranich, V.M. Rubish et al., Influence of composition, exposive, thermal annealing and pressure on structure and optical properties of As-S-Se chalcogenide glasses and thin films // Ferroelectrics, 372, p. 81-86 (2008).

22. I.D. Turyanitsa, L.K. Vodop'yanov, V.M. Rubish et al., Raman spectra and dielectric properties of glasses of the Sb-S-I system // J. Appl. Spectroscopy, 44(5) p. 501-504 (1986).

23. J. Grigas, E. Talik, V. Lazauskas, Splitting of the XPS in ferroelectric SbSI crystalls // Ferroelectrics, 284, p. 147-160 (2003).
24. C.H. Perry, D.K. Agrawal, The Raman spectrum of ferroelectric SbSI // Solid State Communs. 8, p. 225-230 (1970).

25. M.K. Teng, M. Balkanski, M. Massot et al., Optical phonon analysis in the $\mathrm{A}_{\mathrm{V}} \mathrm{B}_{\mathrm{VI}} \mathrm{C}_{\mathrm{VII}}$ compounds // Phys. Status Solidi (b), 62, p. 173-182 (1974).

26. A.V. Gomonnai, I.M. Voynarovych, A.M. Solomon et al., X-ray diffraction and Raman scattering in SbSI nanocrystals // Mat. Res. Bull., 38(13), p. 1767-1772 (2003).

27. D.K. Agrawal, C.H. Perry, Long-wavelength optical phonons and phase transitions in SbSI // Phys. Rev. B, 4(6), p. 1893-1902 (1971). 